\title{
Agôn
}

Revue des arts de la scène

Critiques | Saison 2015-2016

\section{Le Système pour devenir invisible, texte et mise en scène de Guillermo Pisani}

Les simulacres du récit

\section{Caroline Châtelet}

\section{CpenEdition}

Journals

Édition électronique

URL : http://journals.openedition.org/agon/3989

DOI : 10.4000/agon.3989

ISSN : 1961-8581

Éditeur

Association Agôn

Référence électronique

Caroline Châtelet, "Le Système pour devenir invisible, texte et mise en scène de Guillermo Pisani », Agôn [En ligne], Critiques, mis en ligne le 03 mars 2016, consulté le 23 septembre 2020. URL : http://

journals.openedition.org/agon/3989; DOI : https://doi.org/10.4000/agon.3989

Ce document a été généré automatiquement le 23 septembre 2020.

Association Agôn et les auteurs des articles 


\title{
Le Système pour devenir invisible, texte et mise en scène de Guillermo Pisani
}

\author{
Les simulacres du récit
}

Caroline Châtelet

\section{RÉFÉRENCE}

Le Système pour devenir invisible - texte et mise en scène Guillermo Pisani - Compagnie LSDI

1 Le Système pour devenir invisible n'est pas la première pièce écrite par Guillermo Pisani. Néanmoins, on pressent qu'elle marque une étape dans son parcours. D'abord, à la création du texte correspond la naissance de sa compagnie, au titre éponyme. Ensuite, la pièce constitue sa première mise en scène. Une incursion qui amène forcément ce collaborateur du collectif des Lucioles et plus particulièrement de l'acteur, metteur en scène et nouveau directeur de la Comédie de Caen Marcial di Fonzo Bo, à s'exposer sur sa capacité à porter au plateau ses écrits. Et peut-être est-ce cette aptitude de Guillermo Pisani à dépasser sa matière littéraire pour concevoir un objet scénique maîtrisé qui saisit le plus à la découverte du Système pour devenir invisible.

2 Lorsque le spectacle débute, une femme est déjà sur scène, dans un appartement sommairement meublé où trônent six écrans de télévision. Tandis qu'un texte diffusé sur les écrans la décrit avec précision réalisant une performance porno (dont elle serait spécialiste), elle regarde, vautrée dans un fauteuil, une émission de télé allemande. Ladite performance, c'est à la fin de la pièce qu'elle la met à exécution, bouclant la boucle d'un récit qui ne cesse de brouiller les pistes et de creuser jusqu'au trouble les écarts entre les actions et leurs commentaires. Ainsi, entre cette description et sa réalisation, diverses histoires possibles s'entremêlent. Entremêlement de récits, mais de langues aussi: les personnages passent sans cesse de l'allemand au français et inversement, les écrans projetant les traductions. Version \#1, dite en voix off ou en direct par la colocataire de Heiner et performeuse porno: Mia, française vivant en 
marge de la société - c'est-à-dire sans carte bleue ni tout autre moyen d'être "pistée " - est à Berlin afin de subtiliser avec un complice le système pour devenir invisible. Un « système » conçu par Heiner/Doudou, hacker dissident de leur groupuscule. Version \#2, jouée sous nos yeux : Mia est en vacances quelques jours avec son conjoint à Berlin. Tous deux se sont disputés et elle se retrouve chez Heiner/Doudou, rencontré par hasard dans un squatt. Dans les deux cas, Mia couche avec Heiner, rencontre les voisins Inge et Ralfy et passe quelques heures avec le trio. Bibliothécaire intérimaire sauvant des livres du pilon, Inge écrit un scénario, qu'elle vole en réalité à un autre voisin, espionné grâce aux compétences technologiques de Heiner. Quant à Ralfy, il se prend successivement pour le chansonnier est-allemand Wolf Biermann puis pour la chanteuse Nina Hagen (Biermann étant le beau-père de cette dernière). Pour qui connaît un peu le théâtre du dramaturge contemporain argentin Rafael Spregelburd, compatriote de Pisani et de Di Fonzo Bo (que les Lucioles ont plusieurs fois mis en scène), les liens de parentèle sont sensibles. On retrouve un goût commun pour les récits complexes enchâssant les histoires, ainsi que pour la littérature de genre - récits d'espionnages ou fantastiques. On trouve, également, une même façon extrêmement savante et maîtrisée d'injecter dans une narration trépidante des problématiques plus politiques, offrant plusieurs niveaux de lecture. Car ces deux versions superposées de récits entre lesquelles les spectateurs louvoient, via le jeu des comédiens, la voix off ou les traductions et variantes de l'histoire projetées sur les écrans au plateau, énumèrent également différents rapports au militantisme. Et du retrait du monde du groupe de militants dont ferait partie Mia ; au hackisme mis en œuvre par Heiner ; à la figure de Wolf Biermann, dissident déchu de la nationalité est-allemande pour sa critique du régime; aux études philosophiques «auprès de Luc Boltanski » de l'époux de Mia; à Trudy, la colocataire de Heiner, pour qui « le porno peut être un activisme en soi, parce qu'il montre les différentes sexualités "; jusqu'à la conversion exaltée au christianisme de Hagen, ce sont autant de possibilités d'engagement que la pièce déplie. Sans pour autant trancher entre elles. Répondant à ce croisement des choix politiques des personnages, le dispositif scénographique aussi sommaire qu'habile construit des récits parallèles entre lesquels le spectateur est ainsi libre d'aller et venir. Le dédoublement de l'histoire fait partie intégrante de la dramaturgie, la traduction projetée sur les écrans devenant une invention technologique de Heiner permettant aux personnages de communiquer. Les protagonistes se retrouvent donc, au même titre que le public, à devoir s'en remettre à une version, forcément filtrée, de ce qui est énoncé. Une ambiguïté sourde d'autant plus efficace que les six comédiens dominent leur rôle avec brio, sans se laisser déborder par la densité du propos. Ce simulacre généralisé se découvre alors comme une géniale machine à jouer pleine d'astuces - tel ce fameux système de disparition -, où le suspense le dispute sans cesse à la comédie. Quoiqu'éminemment sérieux et documenté dans son propos et ses références, Le Système pour devenir invisible est aussi une pièce pour acteurs, sans didactisme volontariste. En se terminant sur le passage à l'acte de la performeuse porno, qui succède lui-même aux dernières paroles de Mia, la pièce laisse la possibilité à chacun de choisir son camp : «C'est un monde plein de beauté (...) / Et il suffit de se laisser porter par lui (...) / Je n'ai aucune responsabilité (...) / Et je suis libre. » 
Le Système pour devenir invisible, texte et mise en scène de Guillermo Pisani

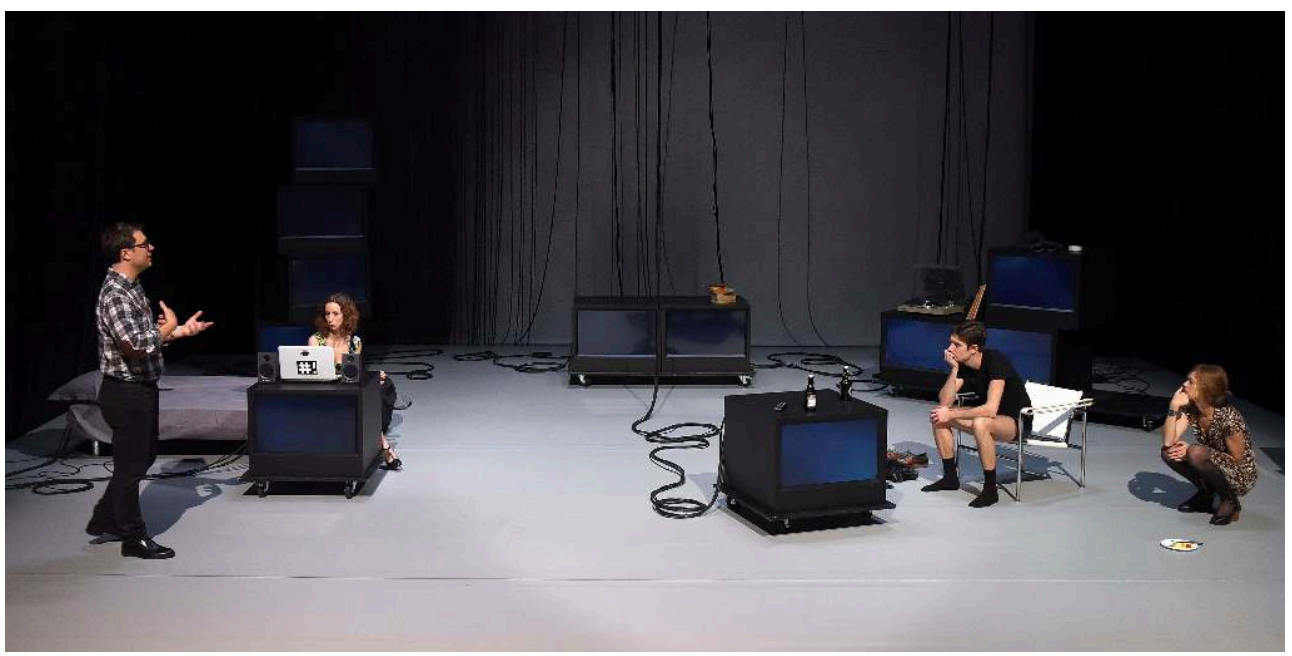

Tristan Jeanne-Valès 